\title{
ANOTHER WAY OF POTENTIATING PHARMACOLOGICAL THERAPY IN TREATMENT-RESISTANT MAJOR DEPRESSIVE DISORDER - PETS !
}

Jorge Mota Pereira1 ${ }^{1}$, Daniela Fonte ${ }^{1}$, Ricardo Teixeira ${ }^{1}$, Serafim Carvalho².

${ }^{1}$ Clínica Médico-Psiquiátrica da Ordem, Psychiatry, Porto, Portugal; ${ }^{2}$ Hospital de Magalhães Lemos, Porto Psychiatric Department, Porto, Portugal.

\section{Background}

TR-MDD is a severe disease, with very low remission rates. The resistance to pharmacotherapy leads to the search of nonpharmacological alternative approaches(1). Animal therapy has been used in patients with psychiatric conditions and the results have been promising(2). However, there have been no studies in TR-MDD patients with pet adoption.

\section{Objectives}

To assess the impact of pet adoption, as an adjuvant to pharmacotherapy, in treatment-resistant Major Depressive Disorder (TR-MDD).

\section{Materials and Methods}

Eighty patients were suggested to adopt a pet, and 30 accepted the challenge. Other 30 patients constituted the control group (no suggestion of pet adoption and no already existing pets). All patients maintained their usual pharmacotherapy. All participants were evaluated at baseline, 4, 8 and 12 weeks for depressive symptoms using HAMD17 and GAF.

\section{Results}

The pet group improved HAMD17 $(p<0.001)$ and GAF $(p<0.001)$ scores at all time points compared to baseline. HAMD17 was significantly lower at 8 and 12 weeks $(p=0.004)$ compared to the control group. GAF was higher in patients in the pet group compared to the control group only at week $12(p=0.011)$. At the end of the study there were neither responders nor remitters in the control group whilst in the pet group $33.3 \%$ of patients responded and $36.3 \%$ remitted $(p=0.001$ and $p<0.001$ compared to the control group, respectively).

\section{Conclusions}

Our results show that a pet contributes to the enhancement of pharmacotherapy effects in patients with TR-MDD. TR-MDD patients that are willing to have a pet should be encouraged to do so.

Table 1 - Baseline demographics and psychiatric profile

\begin{tabular}{|l|c|c|l|}
\hline & $\begin{array}{c}\text { Control group } \\
(\mathbf{n = 3 0})\end{array}$ & $\begin{array}{c}\text { Pet group } \\
(\mathbf{n}=30)\end{array}$ & p value \\
\hline $\begin{array}{l}\text { Age (years), median } \\
\text { (IQR) }\end{array}$ & $52.0(20.0)$ & $50.0(23.0)$ & $0.399^{*}$ \\
\hline HAMD17 total & $12.0(5.0)$ & $14.0(6.0)$ & $0.156^{*}$ \\
\hline score, median (IQR) & $58.0(7.0)$ & $55.0(10.0)$ & $0.279^{*}$ \\
\hline GAF, median (IQR) & & & $1.000^{* *}$ \\
\hline Gender, (n) & & 22 & \\
\hline Women & & & \\
\hline
\end{tabular}

${ }^{*}$ Mann-Whitney test; ${ }^{* *} \mathrm{X}^{2}$ test

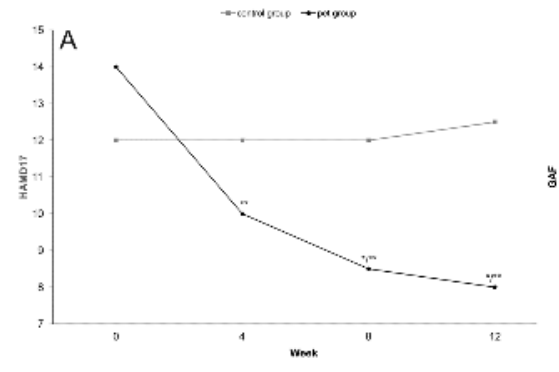

Figure 2 - A) HAMD17 total score variation in the pet group (remitted versus non-remitted); B) GAF variation in the pet group. ${ }^{*} p<0.05$ compared to no remission group. $P$ values from ANCOVA.
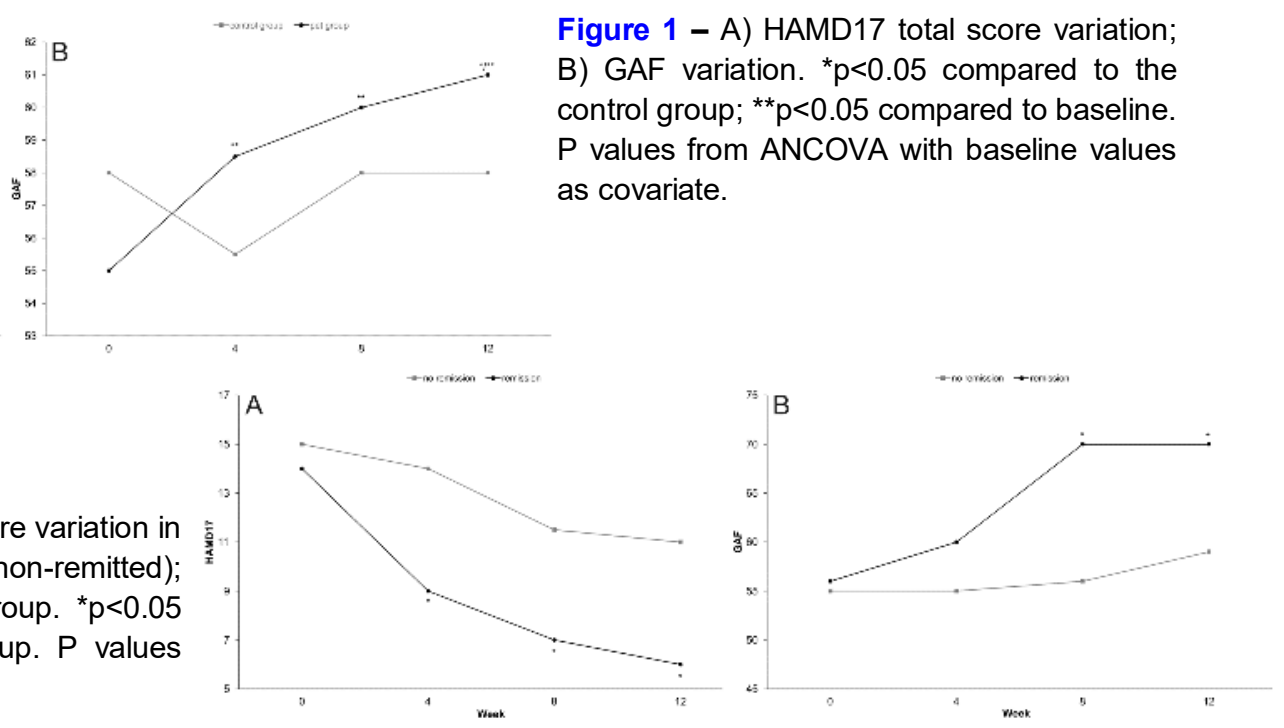